\title{
Variability of the lunar semidiurnal tidal amplitudes in the ionosphere over Brazil
}

\author{
Ana Roberta Paulino ${ }^{1}$, Fabiano da Silva Araújo ${ }^{1}$, Igo Paulino ${ }^{2}$, Cristiano Max Wrasse ${ }^{3}$, Lourivaldo Mota Lima ${ }^{1}$, \\ Paulo Prado Batista ${ }^{4}$, and Inez Staciarini Batista ${ }^{4}$ \\ ${ }^{1}$ Departamento de Física, Universidade Estadual da Paraíba, Campina Grande, Brazil \\ ${ }^{2}$ Unidade Acadêmica de Física, Universidade Federal de Campina Grande, Campina Grande, Brazil \\ ${ }^{3}$ Divisão de Clima Espacial, Instituto Nacional de Pesquisas Espaciais, São José dos Campos, Brazil \\ ${ }^{4}$ Divisão de Heliofísica, Ciências Planetárias e Aeronomia, Instituto Nacional de Pesquisas Espaciais, \\ São José dos Campos, Brazil
}

Correspondence: Ana Roberta Paulino (arspaulino@gmail.com)

Received: 17 May 2020 - Discussion started: 26 May 2020

Revised: 29 November 2020 - Accepted: 29 December 2020 - Published: 17 February 2021

\begin{abstract}
The variability in the amplitudes of the lunar semidiurnal tide was investigated using maps of total electron content over Brazil from January 2011 to December 2014. Long-period variability showed that the annual variation is always present in all investigated magnetic latitudes, and it represents the main component of the temporal variability. Semiannual and triannual (two and three times a year, respectively) oscillations were the second and third components, respectively, but they presented significant temporal and spatial variability without a well-defined pattern. Among the shortperiod oscillations in the amplitude of the lunar tide, the most pronounced ones were concentrated between 7-11 d. These oscillations were stronger around the equinoxes, in particular between September and November in almost all latitudes. In some years, as in 2013 and 2014, for instance, they appeared with a large power spectral density in the winter hemisphere. These observed short-period oscillations could be a result of a direct modulation of the lunar semidiurnal tide by planetary waves from the lower atmosphere and/or due to electrodynamic coupling of $\mathrm{E}$ and $\mathrm{F}$ regions of the ionosphere.
\end{abstract}

\section{Introduction}

Planetary waves are produced by large-scale perturbations in the atmosphere that can have horizontal wavelengths up to $40000 \mathrm{~km}$ around the equator. Those waves can have periods which vary from a couple of days to weeks. Planetary waves are responsible for most of the temporal and spatial variation in the stratosphere, and they also contribute substantially to the variability of the mesosphere and lower thermosphere (MLT). Basically, planetary waves have been classified into three types: (1) quasistationary midlatitude Rossby waves, (2) normal modes and (3) equatorial waves (Smith and Perlwitz, 2015).

Quasistationary Rossby waves are important to the midlatitude dynamics, because they can largely influence the atmospheric fields like wind and temperature, and they are responsible for the distribution of ozone and other trace gases. Rossby normal modes, also known as free modes, are predicted by the theory as oscillatory solutions of Laplace's tidal equation without forcing. Laplace's theory is constructed over an isothermal and non-damping atmosphere; thus, the real conditions of the atmosphere can produce normal modes with some similarities to the theoretical ones. The class of planetary waves which occur near the equator and the most commonly observed in the MLT region are the Kelvin waves, which are classified as low Kelvin waves (periods of $10-15 \mathrm{~d}$ ), fast Kelvin waves (periods of 6-10d) and ultrafast Kelvin waves (periods of 2.5-6d) (Chen and Miyahara, 2012).

Dissipative processes act significantly in the upward propagation of planetary waves in the atmosphere, producing a pronounced damping above $100 \mathrm{~km}$ altitude. Among several mechanisms, cooling by emission of heat and interaction with small-scale waves have been pointed out as the 
most important (e.g., Smith and Perlwitz, 2015, and references therein). However, in the last decades, a large number of studies have shown evidence of oscillations with periods compatible with planetary waves in the thermosphereionosphere (e.g., Forbes, 1996; Pancheva and Laštovička, 1998; Pancheva et al., 2002; Laštovička, 2006; Abdu et al., 2006, 2015; Jonah et al., 2015; Gan et al., 2015; Mo and Zhang, 2020, and references therein). The understanding of how planetary waves can penetrate into the thermosphereionosphere system has been raised as one of the most important topics of research in the coupling of the atmospheric layers. Recent studies have given some insights into this topic (e.g., Forbes et al., 2014; Gasperini et al., 2017), but further observations and investigations are necessary in order to understand this coupling.

The lunar semidiurnal tide with period of $\sim 12.424$ solar hours is the most important Moon oscillation for the atmosphere in terms of amplitudes. Although the generation of the lunar semidiurnal tides comes from the lower levels of the atmosphere due to the Moon's gravitational attraction and interaction with vertical motion of the oceans and solid Earth, the lunar tide can propagate to the thermosphere with less influence by the dissipative process. As the source of the lunar tide is well known, variations associated with the sources are predictable. Then, the lunar tide can be used as an important trace to observe changes in the atmosphere as it propagates vertically. Furthermore, modulation of the lunar semidiurnal tidal amplitudes by planetary waves can be used to explain the presence of these waves in the thermosphere-ionosphere system, which is the main purpose of the present work. Additionally, variability of a long period in the lunar semidiurnal tidal amplitudes is also investigated.

Data from a network of Global Navigation Satellite System (GNSS) receivers over Brazil were used to calculate the amplitudes and phases of the lunar semidiurnal tide in the total electron content (TEC) of the ionosphere from 2011 to 2014 (Paulino et al., 2017). In the present work, the temporal variability of the lunar semidiurnal tidal amplitudes was extensively investigated showing long- $(>60 \mathrm{~d})$ and shortperiod $(<25 \mathrm{~d})$ oscillations.

\section{Analysis and results}

\subsection{Determination of the lunar tide in TEC maps}

The determination of the lunar semidiurnal tides in TEC maps was done according to the Pedatella and Forbes (2010) methodology, and only quiet days were considered $(\mathrm{Kp}<3)$ in the analysis. After eliminating the geomagnetic influences, a Fourier analysis was performed to extract the subharmonics of the solar day (diurnal, semidiurnal and terdiurnal oscillations). Effects of the solar rotation were removed using a $27 \mathrm{~d}$ window moving it forward $1 \mathrm{~d}$ at time to calculate the mean solar day centered in the window. In addition, relative resid- ual was determined by dividing the residual variation of TEC by the TEC average.

In the relative residual data, a least-square analysis in a window of $29 \mathrm{~d}$ was applied using the following equation:

$y(\tau)=\sum_{n=1}^{3} A_{n} \cos \left(n \tau+\phi_{n}\right)$,

where $\tau$ is the lunar time given by $\tau=t-v$, and $v$ is the age of the Moon, which is set to be 0 at the new Moon. The solar time is represented by $t$, and the amplitudes and phases of the lunar tide components are represented by $A_{n}$ and $\phi_{n}$, respectively.

\subsection{Filtering}

A further description of the methodology to calculate the TEC maps over Brazil was provided by Takahashi et al. (2016). TEC maps have also been used to calculate the amplitude and phases of the lunar semidiurnal tide from 2011 to 2014 over Brazil (Paulino et al., 2017). In the present study, the variability due to low and high frequencies in the lunar semidiurnal tide amplitudes observed in those TEC maps is investigated in detail.

Figure 1 shows the filtering process in the amplitudes of the lunar semidiurnal tide calculated at $10^{\circ} \mathrm{S}$ (magnetic).

Figure 1a shows the raw amplitudes in TEC units from 2011 to 2014. One can see that there are low- and highfrequency oscillations in the amplitudes retrieved from the TEC. Figure $1 \mathrm{~b}$ shows the filtered amplitudes considering periods greater than $30 \mathrm{~d}$, and Fig. 1c shows the high frequencies greater than $1 / 30 \mathrm{~d}^{-1}$. This filtering process was done using a Butterworth kernel low-pass filter of order 1. Mathematically this filter can be written as:

filter $=\frac{1}{\sqrt{1-\left(\frac{\Omega}{\Omega_{\mathrm{c}}}\right)^{2 n}}}$,

where $\Omega$ is the frequency, $\Omega_{\mathrm{c}}$ is the cutoff frequency and $n$ is the order (Roberts and Roberts, 1978). This filter is applied to the signal in the domain of the frequency, and then the filtered signal is recovered to the domain of time.

Another important point to be analyzed is the possible influence of the semidiurnal solar tide in the present results since this oscillation is very close to the semidiurnal lunar tide. TEC data collected from February to April 2014 at $30^{\circ} \mathrm{S}, 54^{\circ} \mathrm{W}$ were used to validate the present analysis. Figure 2 shows the original TEC (panel a), amplitudes of the semidiurnal solar tide (panel b), Lomb-Scargle periodogram for the amplitudes of the solar tide (panel c), amplitudes of the semidiurnal lunar tide (panel d) and Lomb-Scargle periodogram for the amplitudes of the lunar tide. This time interval was chosen because it presents a strong quasi $8 \mathrm{~d}$ oscillation in the amplitudes of the semidiurnal lunar tide, which is 
$10^{\circ} \mathrm{S}$
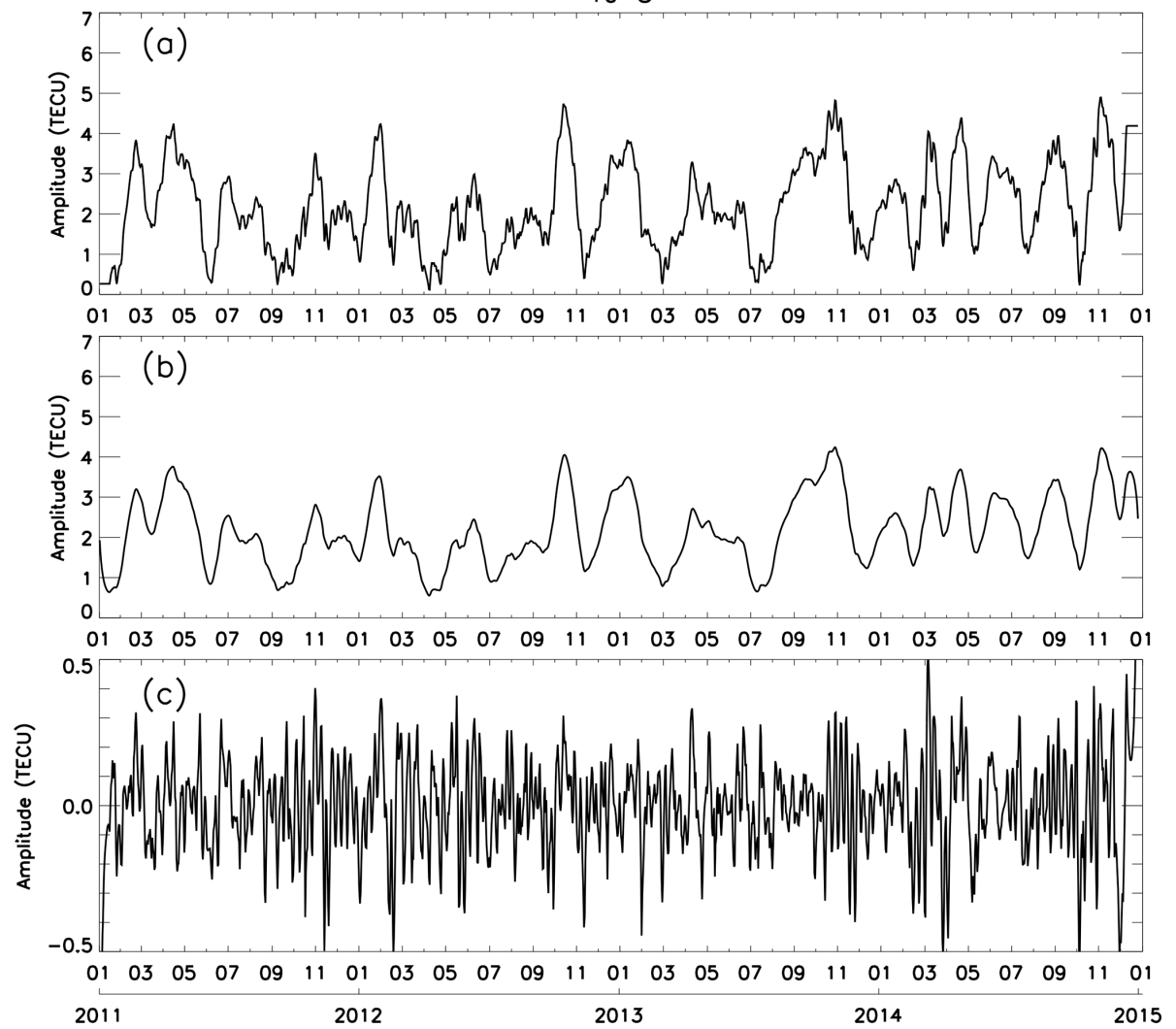

Figure 1. (a) Amplitudes of the lunar semidiurnal tide from 2011 to 2014 calculated at $10^{\circ} \mathrm{S}$ (magnetic latitude). (b) Low frequencies $\left(<1 / 30 \mathrm{~d}^{-1}\right)$ calculated using a Butterworth kernel filter from amplitudes of (a). (c) Same as (b) but for high frequencies $\left(>1 / 30 \mathrm{~d}^{-1}\right)$.

going to be discussed later in the text. Furthermore, these geographic coordinates correspond to one of the most southern points of Brazil, where, in general, the solar semidiurnal tide is strong compared to the equatorial latitudes.

Figure 2a shows an oscillation roughly around $8 \mathrm{~d}$ in the whole data, besides the well pronounced diurnal $(24 \mathrm{~h})$ and semidiurnal $(12 \mathrm{~h})$ oscillations. Figure $2 \mathrm{~b}$ shows that there is no significant oscillation of around $8 \mathrm{~d}$ in the amplitude of the solar semidiurnal tide, and this is confirmed in Fig. 2c. Additionally, Fig. $2 d$ shows that the amplitude of the semidiurnal lunar tide has a well-defined quasi- $8 \mathrm{~d}$ oscillation, in which the confidence level in Fig. 2e appears. These results are very relevant and show that there is no leakage from the semidiurnal solar tide in the present results, and the proposed methodology satisfactorily separates the solar and lunar components.

\subsection{Long-period oscillations}

Considering the filtered amplitudes for periods longer than $30 \mathrm{~d}$, a spectral analysis was performed, and the results are shown in Fig. 3. The Lomb-Scargle periodograms (Lomb, 1976; Scargle, 1982) were calculated using the filtered am- plitudes from 2011 to 2014 for the magnetic latitudes $10^{\circ} \mathrm{N}$, $0^{\circ}$ and $10^{\circ} \mathrm{S}$ and $20^{\circ} \mathrm{S}$.

Figure 3a shows the strong power spectral density (PSD) associated with the annual and semiannual variations. One can also observe that there is a third peak around $120 \mathrm{~d}$, i.e., a triannual variation. Similar patterns to what are observed at $10^{\circ} \mathrm{N}$ can be observed at $10^{\circ} \mathrm{S}$ (Fig. 3c) and $20^{\circ} \mathrm{S}$ (Fig. 3d) as well. At $0^{\circ}$ (Fig. 3b), annual and semiannual variations were strong; additionally, the triannual variation was weak compared to the other latitudes. Comparing $10^{\circ} \mathrm{N}$ to $10^{\circ} \mathrm{S}$, it is clear that there are more significant peaks of oscillation in the south, indicating that the long oscillations are not symmetrical with respect to the magnetic equator.

In order to investigate when the periodicities shown in Fig. 3 appear more frequently in the dataset, a wavelet analysis was performed, and the results are shown in Fig. 4 with the respective magnetic latitudes. These wavelet charts were calculated based on the methodology of Torrence and Compo (1998).

Figure 4 shows that the annual variation is always present in the amplitude of the lunar tide. Figure $4 \mathrm{a}$ shows that the semiannual variation was present in the two first years, and the triannual variation appears more pronounced in the beginning of 2013, which can be composed of oscillations from 

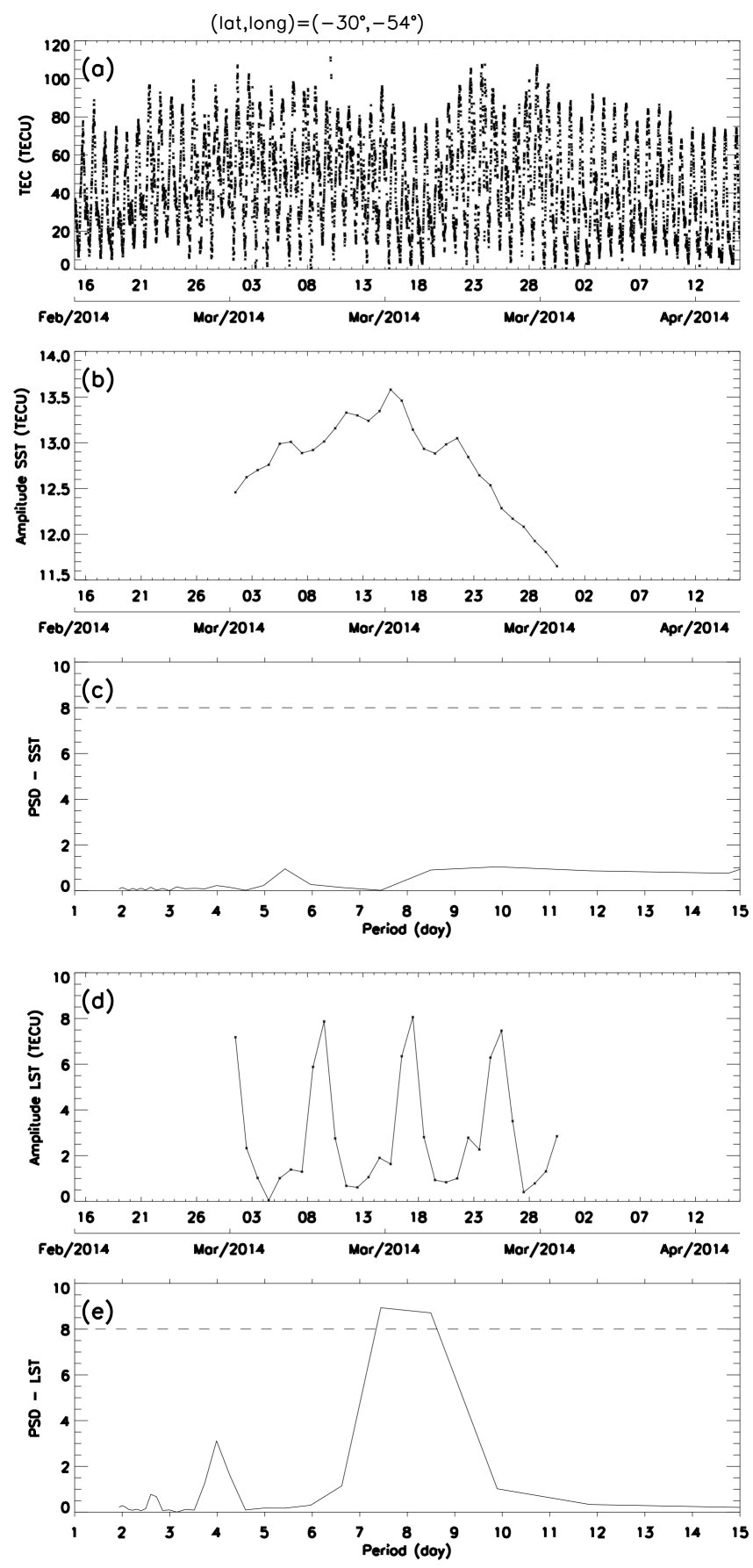

Figure 2. (a) TEC collected at $30^{\circ} \mathrm{S}$ and $54^{\circ} \mathrm{W}$ from February to April 2014. (b) Amplitudes of the semidiurnal solar tide calculated from (a). (c) Periodogram for the amplitudes of the semidiurnal solar tide. (d) Amplitudes of the semidiurnal lunar tide calculated from (a). (e) Periodogram for the amplitudes of the semidiurnal lunar tide. The horizontal dashed line represents the confidence level of $99 \%$.

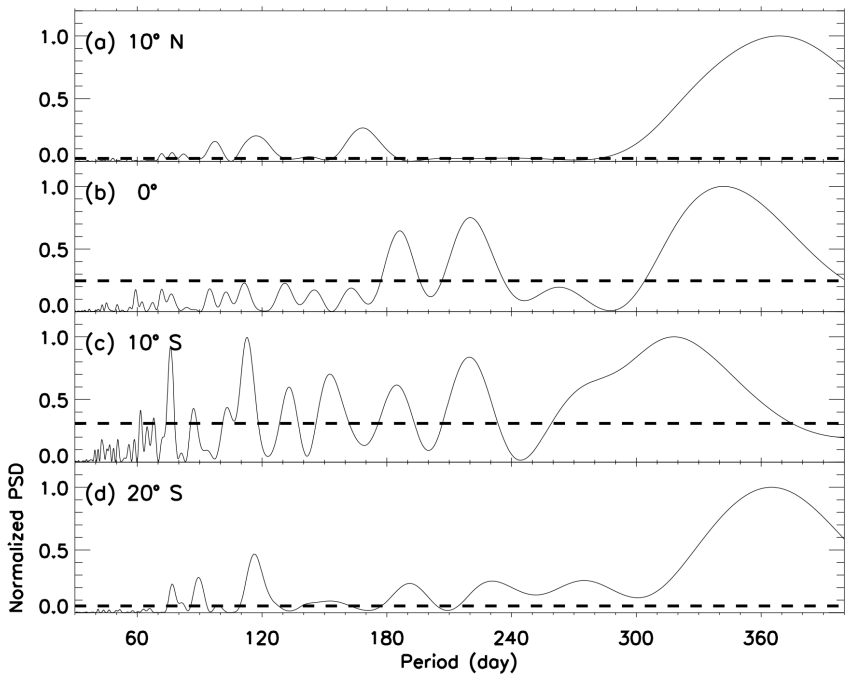

Figure 3. Lomb-Scargle periodogram for (a) $10^{\circ} \mathrm{N}$, (b) $0^{\circ}$, (c) $10^{\circ} \mathrm{S}$ and (d) $20^{\circ} \mathrm{S}$. The horizontal dashed lines represent the confidence level of $99 \%$, i.e., false alarm probability of 0.01 .

80 to $120 \mathrm{~d}$. In the beginning of 2014 , the triannual variation appeared as well.

Figure $4 \mathrm{~b}$ (magnetic equator) shows that the semiannual variations were strong in the end of 2012 and beginning of 2013 with spreading out of this peak to over $200 \mathrm{~d}$. Figure $3 \mathrm{~b}$ also shows this behavior in the Lomb-Scargle chart. One can also observe short oscillations of $70-80 \mathrm{~d}$ in the beginning of 2013 and 2014.

Figure $4 \mathrm{c}$ shows that the semiannual oscillation in the amplitude of the lunar tide becomes stronger than the annual oscillation in the second half of 2013. It is important to observe that the triannual oscillation was present in the amplitude of the lunar tide from 2011 to March 2013 and became very strong at the end of this time range, compared to the other latitudes and times. Figure $4 \mathrm{c}$ also shows oscillations with periods shorter than $100 \mathrm{~d}$ along the whole observed time.

Figure $4 \mathrm{~d}$ shows that the triannual oscillation appeared in 2013 and 2014, and at this magnetic latitude, the semiannual oscillation was weaker than the triannual. Oscillations of 70$80 \mathrm{~d}$ have the same occurrence observed at $10^{\circ} \mathrm{N}$.

\subsection{Short-period oscillations}

The short-period oscillations observed in the amplitudes of the lunar tide were also investigated in this work. These oscillations are important, because they can be associated with planetary waves revealing relevant aspects in the atmosphere-ionosphere coupling from below.

Figure 5 shows the Lomb-Scargle periodogram for the same latitudes used in Fig. 3 but considering only periods shorter than $25 \mathrm{~d}$. These periodograms were calculated using the high frequencies in the amplitudes of the lunar semidiurnal tide as exemplified in Fig. 1c. Figure 5a to d, which 

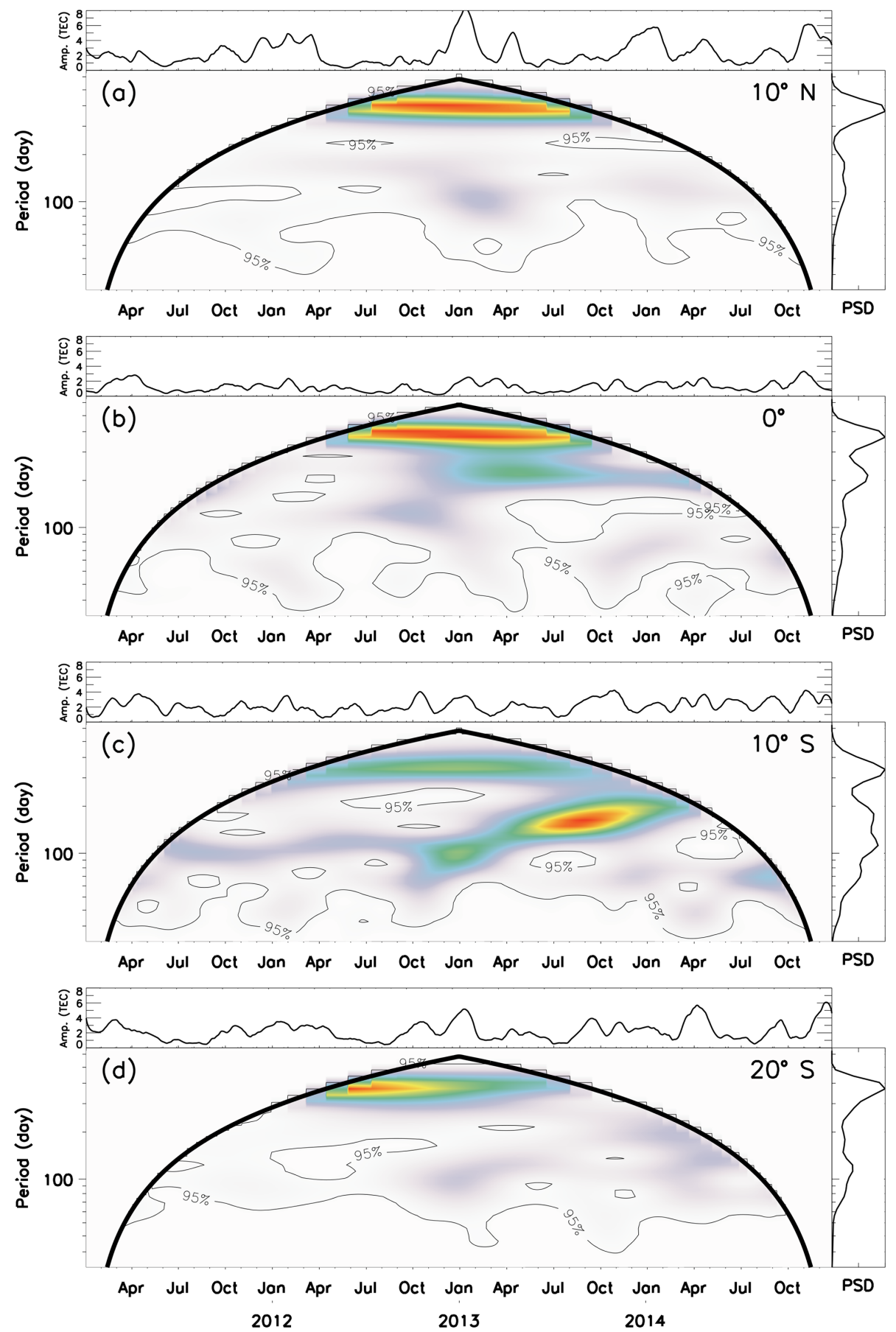

Figure 4. Wavelet analysis for (a) $10^{\circ} \mathrm{N}$, (b) $0^{\circ}$, (c) $10^{\circ} \mathrm{S}$ and (d) $20^{\circ} \mathrm{S}$. The heavy black lines in the contours represent the cone of influence. The light black lines show confidence levels of $95 \%$.

represent the magnetic latitudes from $10^{\circ} \mathrm{N}$ to $20^{\circ} \mathrm{S}$, shows significant periodicities of 7-12 d from 2011 to 2014. Hereafter, we are going to refer to these oscillations as quasi- $8 \mathrm{~d}$ (Q8D) oscillations, although sometimes they can be either shorter or longer than $8 \mathrm{~d}$. Similar assumption were used by Ahlquist (1982). Please note that other long periods were also observed above the significance levels, but they were more sporadic than the Q8D oscillation as will be shown later.

In order to further investigate the temporal evolution of the short-period oscillation in the amplitudes of the lunar semidiurnal tide, wavelet analysis was performed for each year of observations, and the results are shown in Figs. 6, 7, 8 and 9. One can observe that Q8D is the dominant oscillation along 


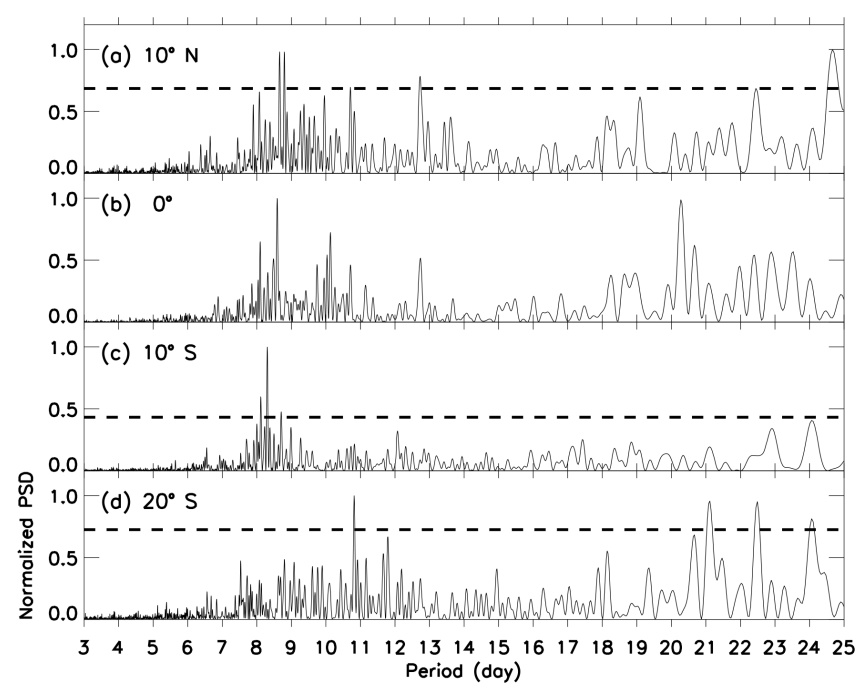

Figure 5. Same as Fig. 2 but considering only periods shorter than $25 \mathrm{~d}$. Note that at $0^{\circ}$, all periodicities were below the confidence level since the amplitudes were smaller compared to the other latitudes.

the whole period of observation. Some particularities are also observed in each year, mainly regarding the epoch of the year in which the Q8D wave is stronger.

Figure 6 shows the wavelet results for the amplitudes of the lunar semidiurnal tide in 2011. The Q8D oscillation was stronger from September to November in almost all latitudes. There was a secondary peak of this oscillation from midFebruary up to April, except at $10^{\circ} \mathrm{S}$.

Figure 7 shows the results for 2012. Again the Q8D oscillation was the most important oscillation, but it appeared more frequently through the year, especially out of the magnetic equator. One different aspect was that the Q8D oscillation was strong in February at $10^{\circ} \mathrm{N}$ and in May at $10^{\circ} \mathrm{S}$.

In 2013 (Fig. 8), the strength of the Q8D oscillation was more concentrated in a few months. At $10^{\circ} \mathrm{N}$, the Q8D oscillation had a larger power spectral density in January and February. At 0 and $10^{\circ} \mathrm{S}$, the oscillation appeared with more intensity from late October to December. At $20^{\circ} \mathrm{S}$, there were two peaks of the Q8D oscillation in April and May.

Figure 9 shows the power spectral density contour for 2014. One can observe a regular behavior of the Q8D oscillation with two peaks around the equinox months.

An important result revealed from the observations is that the Q8D oscillation is always present in the equinox months. From September to November in almost all latitudes and years it was the dominant oscillation. One can also observe that the Q8D oscillation appears strong during the winter in 2012 and 2013 for some magnetic latitudes.

\section{Discussion and summary}

It is well known that the lunar semidiurnal tide has a predictable source. Thus, short and long variations observed in the amplitudes must reveal changes in the atmosphere where this tidal component is propagating. For instance, annual and semiannual variations in the amplitudes of the lunar tide have also been observed in the mesosphere and lower thermosphere (MLT) neutral wind (Paulino et al., 2015). Triannual variations have been observed and simulated in some atmospheric fields as well (e.g., Pedatella et al., 2012; Pedatella, 2014). However, more investigation is necessary to better understand the reason for that variability.

The results from Figs. 3 and 4 show that the annual variation is always present in the amplitudes of the lunar semidiurnal tide in the TEC. At the magnetic equator, the PSD of the annual variation is comparable to the semiannual variation, for instance. However, far from the equator, the annual variation is stronger. Furthermore, it seems that the annual variation is out of phase at this latitude compared to the annual variation observed in MLT winds (Fig. 3, bottom row of Paulino et al., 2015); i.e., the annual variation maximizes around January for all latitudes in the TEC, and it maximizes around November in the MLT winds. This reinforces the idea that the lunar tide obeys the changes in the atmosphere, and the observed variability is not due to changes in the sources.

Although the semiannual oscillation arose as the second peak in the Lomb-Scargle periodogram (Fig. 3) from 2011 to 2014, it appeared sporadically and with more intensity in lower latitudes. In contrast, the TEC observed in Brazil shows a semiannual variation and has maxima around the equinox during both low and high solar activities (Jonah et al., 2015).

The triannual variation with a period of around $120 \mathrm{~d}$, on average, was the third peak found in the amplitudes of the semidiurnal tide. It was sporadic at $10^{\circ} \mathrm{N} ; 0^{\circ}$; and $20^{\circ} \mathrm{S}$. At $10^{\circ} \mathrm{S}$, it was present in almost the whole period of observation and it was stronger than the semiannual oscillation during the first two years of observations, except at $20^{\circ} \mathrm{S}$. Oscillations with $70-80 \mathrm{~d}$ period were also observed in all latitudes sporadically, mainly in the beginning of 2013 and 2014. In Paulino et al. (2017), it is possible to see that the triannual oscillation appears evident at magnetic latitudes out of the equator. It is probable that the combination of the annual variation with maximum in the austral summer months and semidiurnal variation with maximums around the equinoxes (matching with the TEC maximums) is producing the triannual variation in the amplitudes of the lunar semidiurnal tide.

Figure 1a shows roughly a short-period oscillation in the amplitudes of the lunar tide which can be observed in all studied latitudes over Brazil. Sometimes, this short-period oscillation is stronger and sometimes it is very tenuous. This behavior is quite interesting, because it was also observed before (see Fig. 3 of Paulino et al., 2017). 

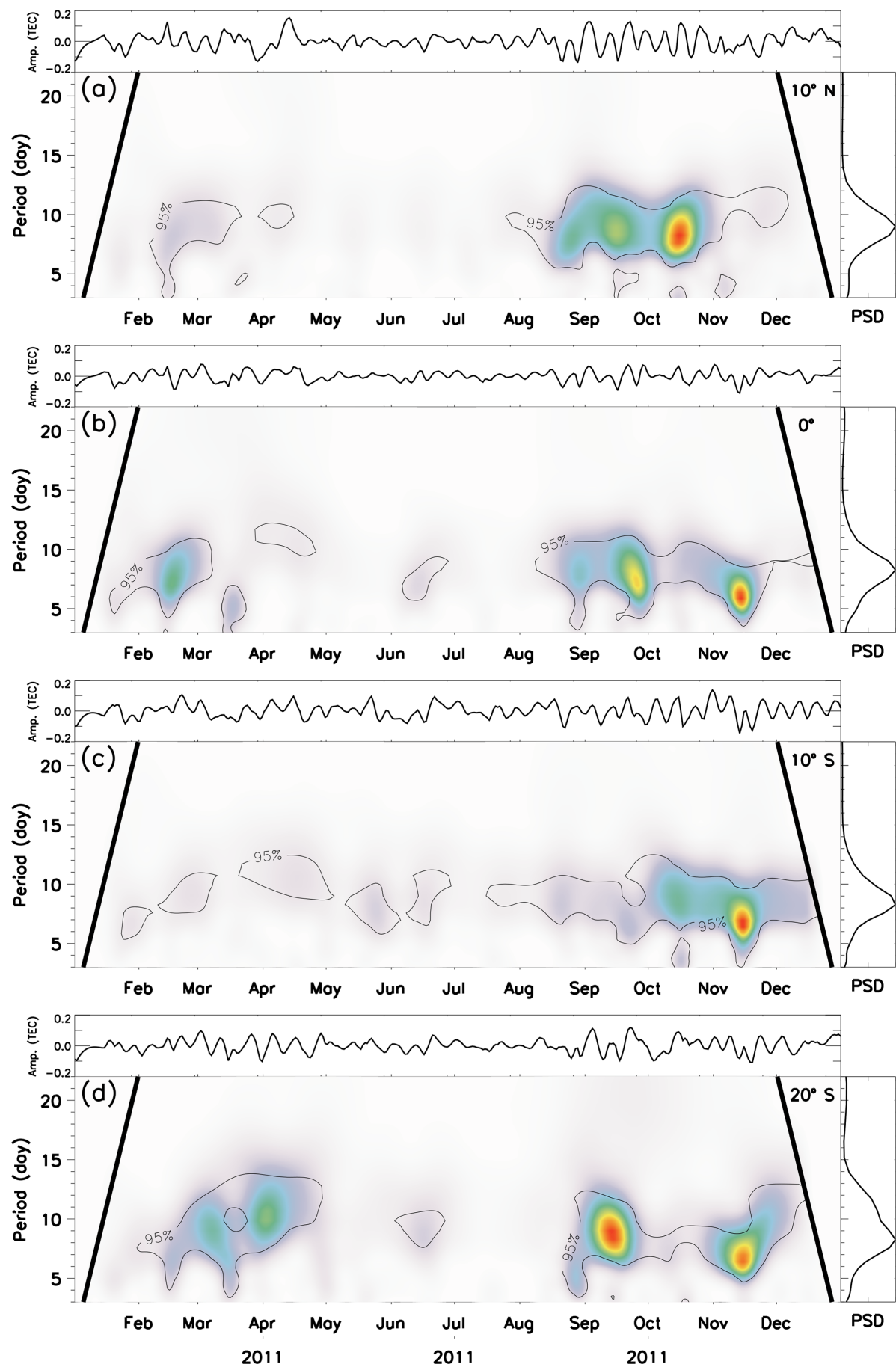

Figure 6. Same as Fig. 3 but considering only periods shorter than 25 d during 2011.

An interesting aspect reveled in this work was the periodicity close to $8 \mathrm{~d}$. Based on the literature, there are two kinds of large-scale waves with periods close to $8 \mathrm{~d}$ : (1) fast Kelvin waves (e.g., Abdu et al., 2015, and references therein) and (2) quasi-10 d planetary waves (e.g., Forbes and Zhang, 2015; Yamazaki and Matthias, 2019).
Fast Kelvin waves have been observed with periods of typically $6-10 \mathrm{~d}$. It is a kind of wave trapped in the equatorial region which has characteristics of gravity waves; i.e., it obeys the dispersion relation of gravity waves. Fast Kelvin waves are typically observed with large amplitude in the zonal wind component and insignificant amplitudes in the meridional one. As the present Q8D oscillation was observed close to 

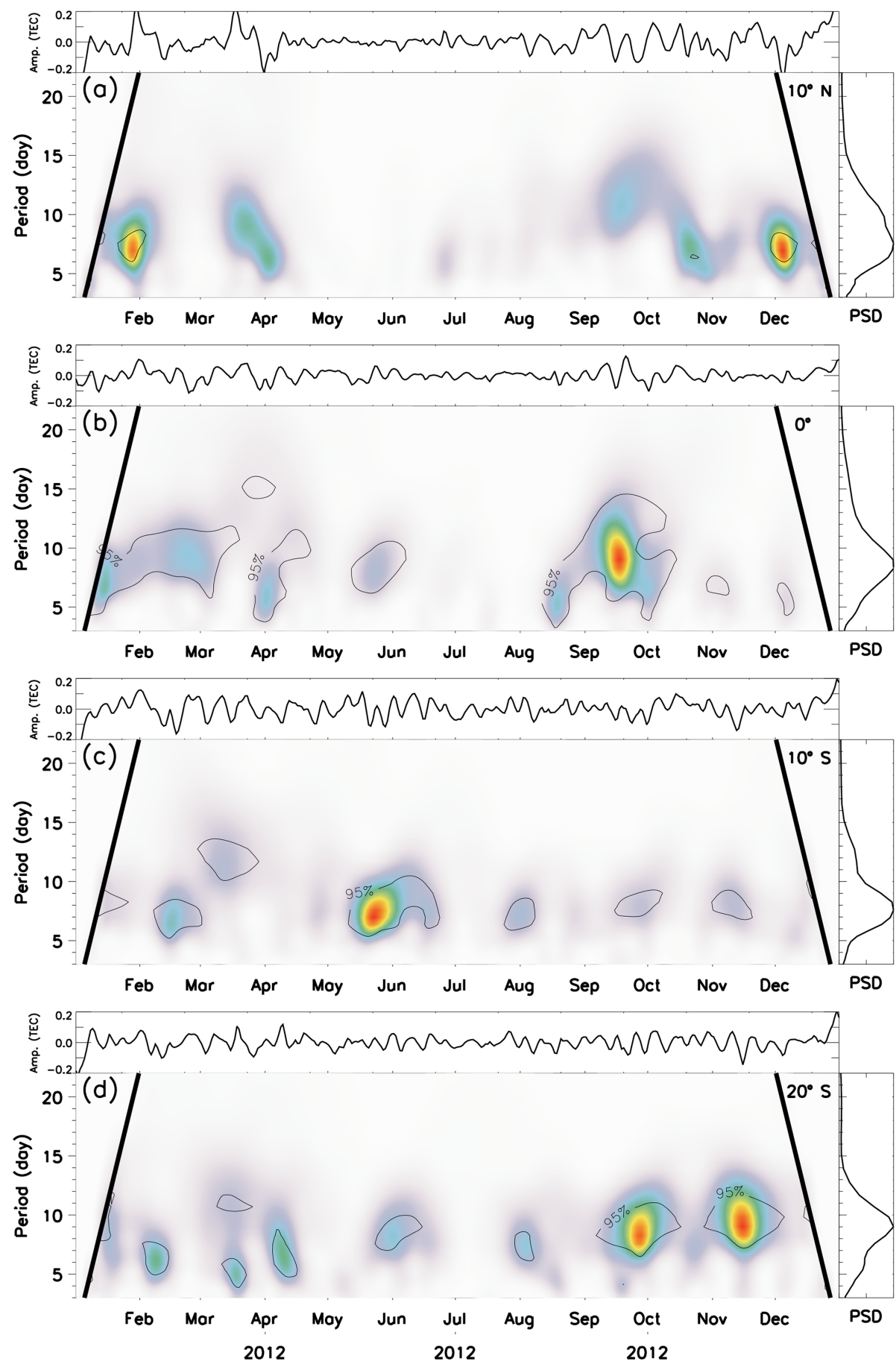

Figure 7. Same as Fig. 5 but for 2012.

the equator as well as at $20^{\circ}$ magnetic latitude, which can be out of the tropics in the western part of Brazil, this modulation can have a contribution of other oscillations as well. Some observations have shown that the amplitudes of the Fast Kelvin wave dominate in altitudes below $90 \mathrm{~km}$ (e.g., Lieberman and Riggin, 1997). Dhanya et al. (2012) found periodicities close to $8 \mathrm{~d}$ in the equatorial electrojet current and in the MLT winds and associated that oscillation to Fast Kelvin waves. Abdu et al. (2015) also observed a Q8D oscillation in the vertical drift of the $\mathrm{F}$ region which modulated the spread-F development.

Figure 10 shows the zonal (solid line) and meridional (dashed line) thermospheric mean wind at 00:00 UT measured by two Fabry-Pérot interferometers deployed at $\mathrm{Ca}$ - 

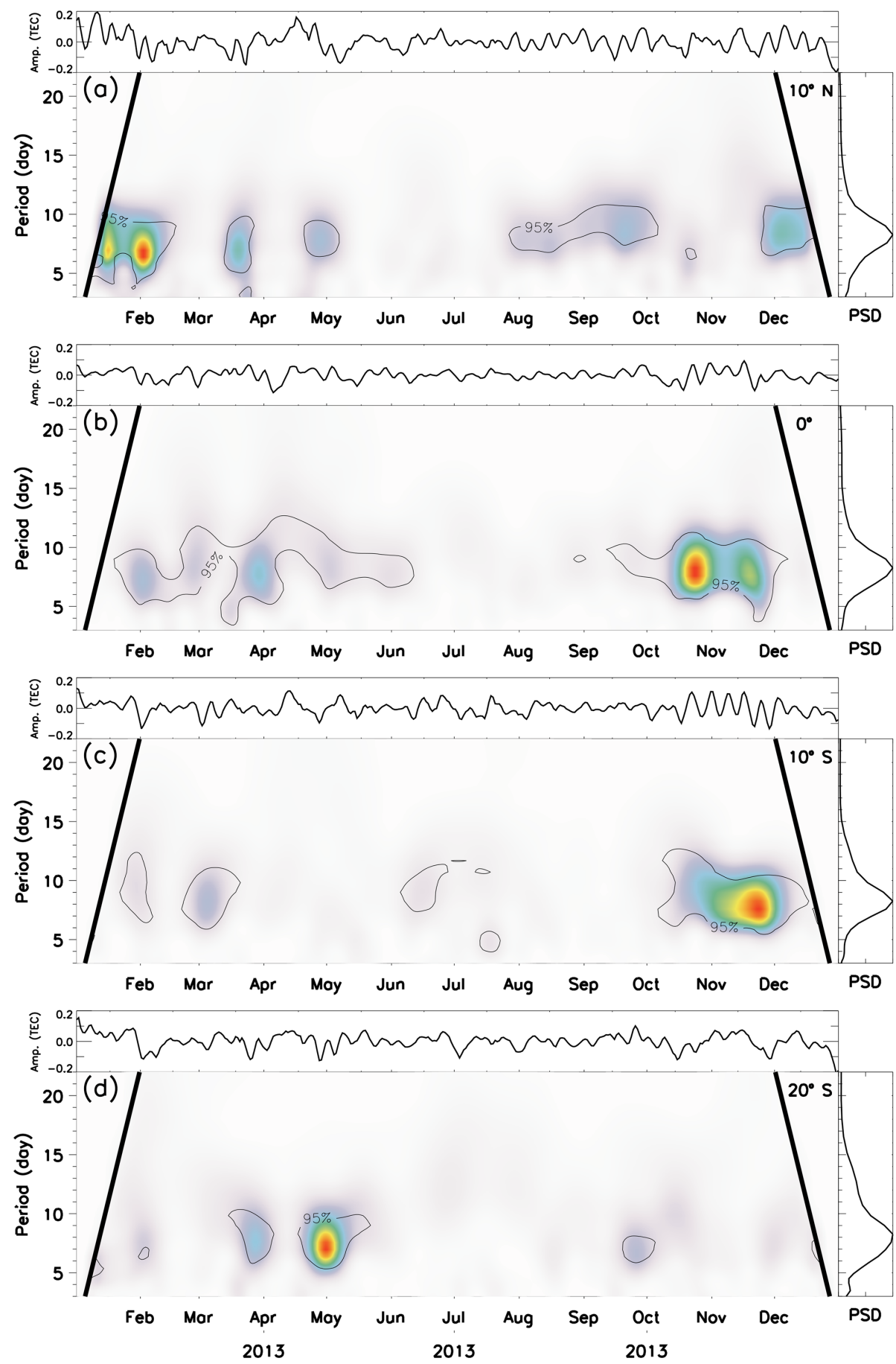

Figure 8. Same as Fig. 5 but for 2013.

jazeiras $\left(6.9^{\circ} \mathrm{S}, 38.5^{\circ} \mathrm{W}\right)$ and São João Cariri $\left(7.4^{\circ} \mathrm{S}\right.$, $36.5^{\circ} \mathrm{W}$ ) during November 2013. Further details about the operations of those instruments can be found in Makela et al. (2009). One can observe that there is an almost in-phase oscillation of about 1 week in the wind field, possibly suggesting the same origin as the observed Q8D oscillation in the amplitude of the lunar tide during this epoch.
Figure 11 shows the Lomb-Scargle periodogram for those data. A strong oscillation of $\sim 6 \mathrm{~d}$ can be observed, and it is likely associated with the presence of fast Kelvin waves in the equatorial zone. One can also observe a peak of around $10 \mathrm{~d}$ in both components; however, it was below the confidence level. 

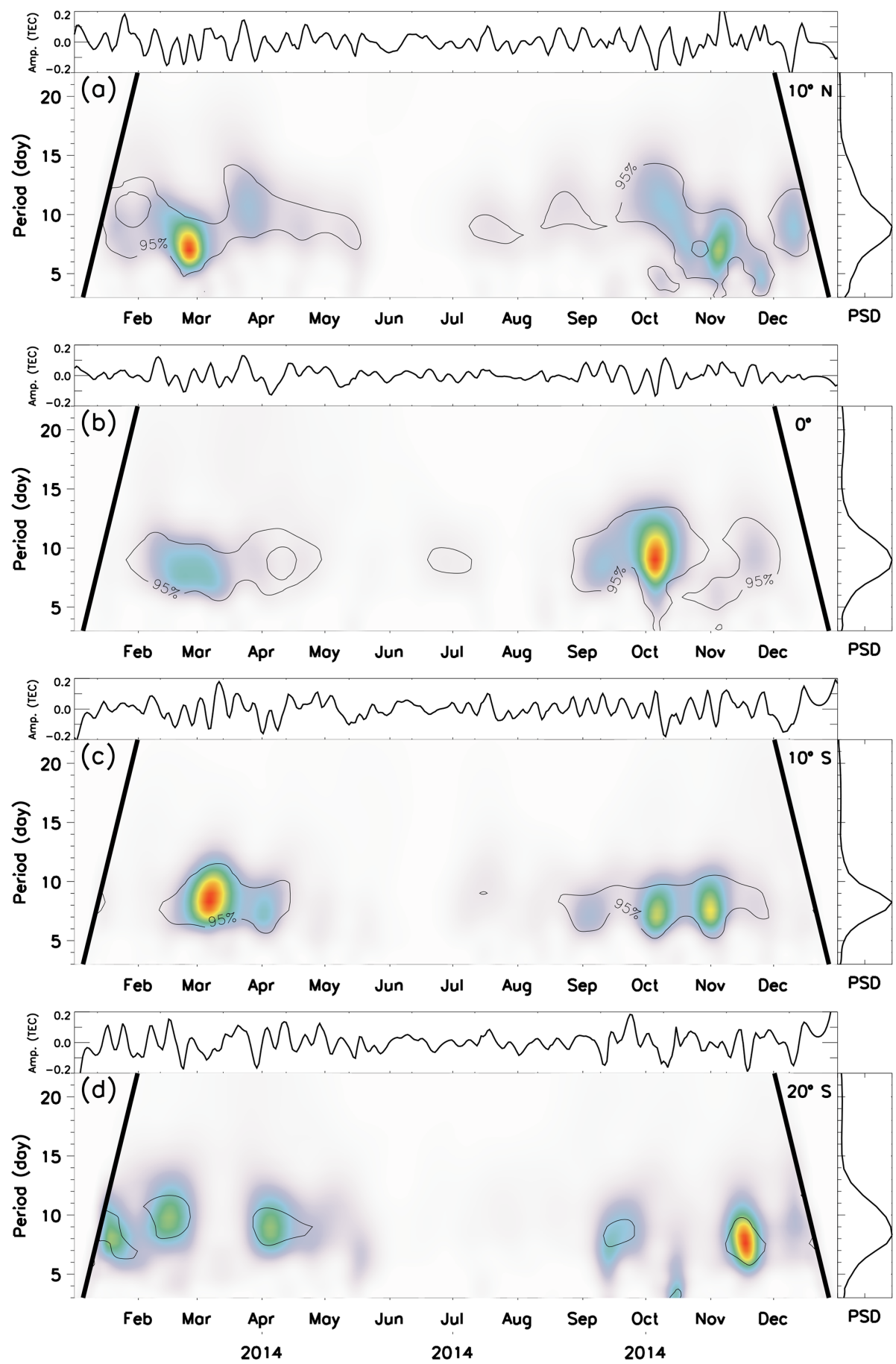

Figure 9. Same as Fig. 5 but for 2014.

In the past years, interest in studying the quasi- $10 \mathrm{~d}$ wave (Q10DW) has recovered, primarily due to its association with polar sudden stratospheric warmings (SSWs) (Yamazaki and Matthias, 2019; Mo and Zhang, 2020). Another motivation was the long-term observation from satellites that allows researchers to investigate seasonality, year-to-year vari- ation and spatial (latitude $\times$ longitude $\times$ altitude) dependencies (Forbes and Zhang, 2015; John and Kumar, 2016).

Although the present results concentrate on the oscillations around $8 \mathrm{~d}$ in the amplitudes of the semidiurnal lunar tide, these oscillations have some characteristics that are similar to the Q10DWs as pointed out by Forbes and Zhang (2015). For instance, in some years, they have large ampli- 


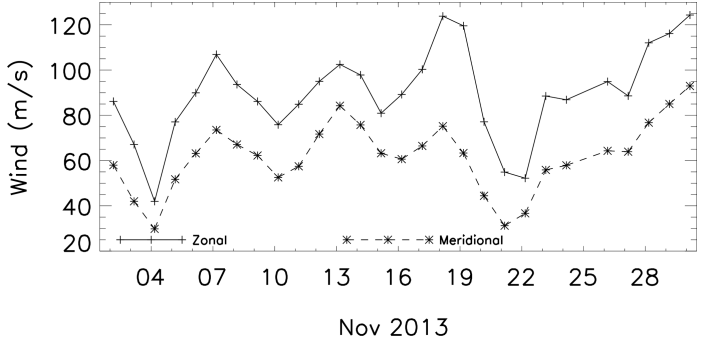

Figure 10. Zonal (solid line) and meridional (dashed line) mean wind components measured by two Fabry-Pérot interferometers over Cajazeiras and São João do Cariri, measured at 00:00 UT during November 2013.

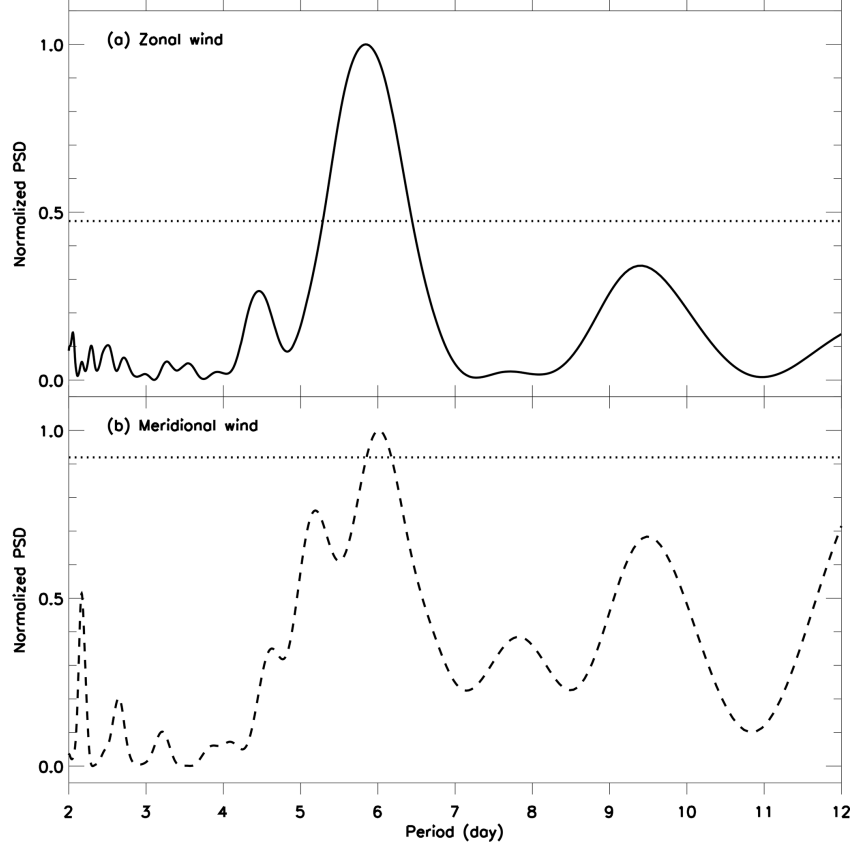

Figure 11. Lomb-Scargle periodogram for (a) zonal and (b) meridional wind during November 2013 in the thermosphere over the equatorial region. Horizontal dotted line represents a significance level of $95 \%$, i.e., false alarm probability of 0.05 .

tudes during the equinox and winter months in both hemispheres.

Observation of waves or oscillations with periods of $8-10 \mathrm{~d}$ has been made in the thermosphere-ionosphere. For example, Forbes (1996) found Q10DW oscillations in the mesopause and lower thermosphere region using data from medium-frequency (MF) radar and a magnetometer. Pancheva and Laštovička (1998) observed fluctuations of 7-8 d from November to December 1994 during an international campaign. Abdu et al. (2006) studied variation in the equatorial electrojet (EEJ) current and in the MLT wind and showed the presence of an 8-12 d oscillation around the equinox of 1999 in the equatorial region. Jacobi et al. (2007) observed 7-12 d waves in the TEC maps over the European

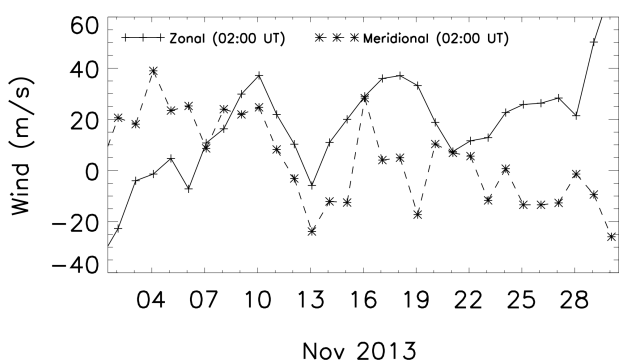

Figure 12. Zonal (solid line) and meridional (dashed line) wind components at $93 \mathrm{~km}$ height over Cachoeira Paulista, measured at 02:00 UT during November 2013.

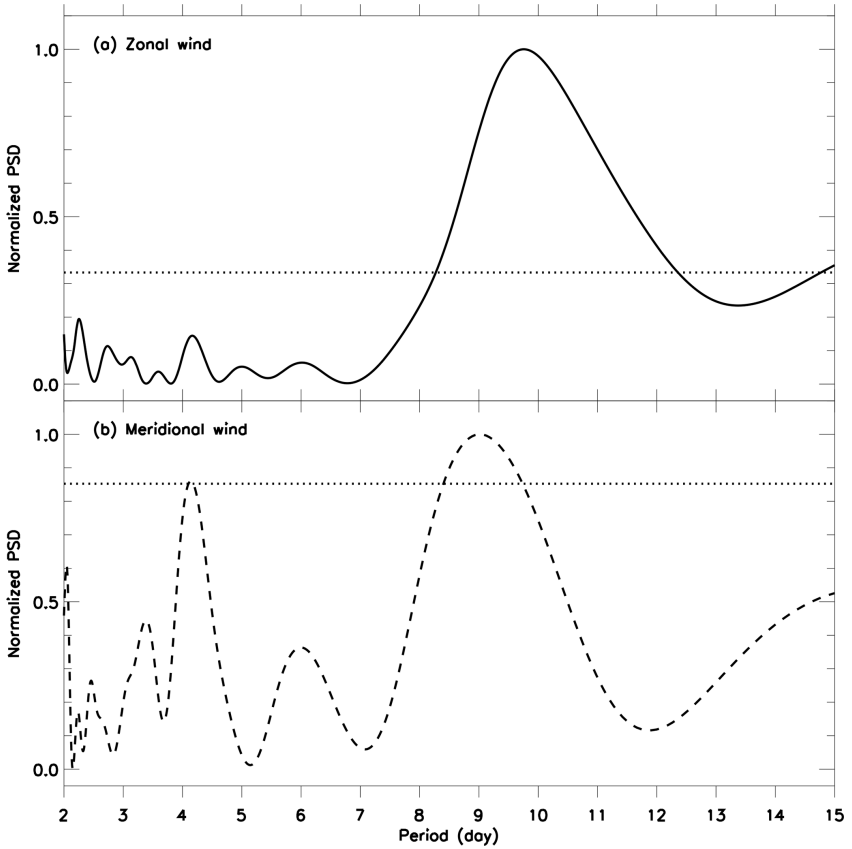

Figure 13. Lomb-Scargle periodogram for (a) zonal and (b) meridional wind during November 2013 at $93 \mathrm{~km}$ altitude over Cachoeira Paulista. Horizontal dotted line represents a significance level of $95 \%$, i.e., false alarm probability of 0.05 .

region. Jonah et al. (2015) also observed 8-10 d oscillations in TEC over Brazil, primarily around the equinoxes. More recently, comprehensive studies on Q10DWs using satellite data presented some important temporal and spatial characteristics of these waves below $110 \mathrm{~km}$ altitude (Forbes and Zhang, 2015; John and Kumar, 2016). Additionally, Yamazaki and Matthias (2019) and Mo and Zhang (2020) presented results associating the Q10Ws to sudden stratospheric warming events.

It is important to note that the observations above showed periods varying from 8 to $10 \mathrm{~d}$ in both the mesosphere and thermosphere-ionosphere. Forbes and Zhang (2015) showed slight variation ( $0.4 \mathrm{~d}$ ) in the period of Q10W (9.7 to $9.9 \mathrm{~d}$ ) and concluded that the Doppler shift produced by the hori- 
zontal wind can change the period of the wave. The present study uses amplitudes of the lunar semidiurnal tide in lunar time; i.e., the lunar day is about $0.036 \mathrm{~d}$ longer than solar day. Assuming that the observed oscillation has a period of $8.5 \mathrm{~d}$ in lunar time, it corresponds to $8.806 \mathrm{~d}$ in solar time. However, this is not enough to explain the discrepancy between the observed period of the Q10DW in the lower atmosphere and the present results.

Figure 12 shows the horizontal wind at $93 \mathrm{~km}$ altitude over Cachoeira Paulista $\left(22.7^{\circ} \mathrm{S}, 45.0^{\circ} \mathrm{W}\right)$ during November 2013 measured at 02:00 UT (universal time). Further details about the wind measurements using meteor radar have been published elsewhere (e.g., Paulino et al., 2012). The temporal evolution of the winds shows some periodic oscillations.

Figure 13 shows the Lomb-Scargle periodogram of the wind including all temporal measurements at $93 \mathrm{~km}$. A quasi$10 \mathrm{~d}$ oscillation is shown in both zonal and meridional components of the horizontal wind. In the zonal component the peak of the oscillation was concentrated at $9.7 \mathrm{~d}$, while in the meridional one the peak was at $\sim 9 \mathrm{~d}$. The presence of this simultaneous oscillation in the MLT wind strongly suggests that the observed oscillation in amplitude of the lunar tide during November 2013 could have a contribution of this oscillation, at least, out of the equator. But the coupling mechanism needs further investigations.

The main results of this investigation can be summarized as follows:

- There is a strong temporal variability in the amplitudes of the lunar semidiurnal tides calculated in the TEC maps over Brazil from 2011 to 2014.

- Annual variation in the lunar semidiurnal tide is always present in all observed latitudes, and it is dominant in lower latitudes.

- Semiannual and triannual ( $\sim 120 \mathrm{~d})$ oscillations were, respectively, the second and third most important longperiod oscillations observed in the amplitudes of the lunar tide. However, it was observed that there is temporal and spatial variability in these oscillations, which allow them to become dominant in a given time interval and latitude range.

- The observed dominant short-period oscillations in the amplitudes of the lunar semidiurnal tide had periods between 8-11 d, with maxima around the equinoxes. In some years, such as 2013 and 2014, the peaks occurred in the winter.

- Coincident measurements of the horizontal wind during November 2013 show the presence of a quasi-10 d oscillation in MLT at low latitudes $\left(23^{\circ} \mathrm{S}\right)$ and quasi-6 d oscillation in the equatorial thermosphere.

Based on the present main results for the short-period oscillations in the amplitudes of the lunar semidiurnal tide, i.e., the Q8D oscillation, it is clear that there is a discrepancy between the observed Q8D oscillation and other oscillations observed in the wind. Additionally, according to the theory of planetary waves, the dissipative process into the thermosphere does not allow for direct propagation of these wave into high levels. Then, an explanation for observation of planetary waves in the thermosphere-ionosphere has been suggested, which is basically based on two possibilities: (1) modulation of the tidal amplitudes, especially the semidiurnal components which can propagate to higher altitudes into the thermosphere, and/or (2) through the theory of dynamo on the electrodynamics of the ionosphere. The present results suggest that maybe a combination of these two possibilities would be necessary to explain the observed modulation in the amplitude of the lunar semidiurnal tide. However, further investigations are necessary to understand this coupling mechanism.

Data availability. The TEC maps used in this work are available online on the EMBRACE website (http: //www2.inpe.br/climaespacial, last access: 10 February 2021). Meteor winds can be requested from Lourivaldo Mota Lima (lourivaldo_mota@yahoo.com.br). Thermospheric winds for São João do Cariri and Cajazeiras can be downloaded from the CEDAR Madrigal Database (http://cedar.openmadrigal.org, last access: 10 February 2021).

Author contributions. ARP wrote the article and performed the analysis in the database. FdSA worked on the Lomb-Scargle periodograms. IP revised the article and helped with some analysis of the data. CMW provided the TEC maps. LML provided the meteor winds. PPB is responsible for the meteor winds and revised the article. ISB also revised the article.

Competing interests. The authors declare that they have no conflict of interest.

Acknowledgements. Ana Roberta Paulino thanks Coordenação de Aperfeiçoamento de Pessonal de Nível Superior (CAPES) for the scholarship. Ana Roberta Paulino, Igo Paulino, Cristiano Max Wrasse and Inez Staciarini Batista thank Conselho Nacional de Desenvolvimento Científico e Tecnolóligo (CNPq) for the financial support. Ana Roberta Paulino and Igo Paulino thank the Fundação de Amparo à Pesquisa do Estado da Paraíba. Wavelet software was provided by Christopher Torrence and Gilbert Compo and is available at: http://paos.colorado.edu/research/wavelets/ (last access: 10 February 2021). The authors thank Ricardo A. Buriti, Jonathan J. Makela and John W. Meriwether for kindly providing the Fabry-Pérot interferometer data.

Financial support. This research has been supported by the Conselho Nacional de Desenvolvimento Científico e Tec- 
nológico (grant nos. 460624/2014-8, 303511/2017-6, 307653/20170, 405555/2018-0 and 306844/2019-2), Coordenação de Aperfeiçoamento de Pessoal de Nível Superior (Prêmio CAPES de tese 2014) and Fundação de Amparo à Pesquisa do Estado da Paraíba (PRONEX grant 002/2019).

Review statement. This paper was edited by Ana G. Elias and reviewed by Federico Gasperini and one anonymous referee.

\section{References}

Abdu, M., Ramkumar, T., Batista, I., Brum, C., Takahashi, H., Reinisch, B., and Sobral, J.: Planetary wave signatures in the equatorial atmosphere-ionosphere system, and mesosphere- Eand F-region coupling, J. Atmos. Sol.-Terr. Phy., 68, 509-522, https://doi.org/10.1016/j.jastp.2005.03.019, 2006.

Abdu, M. A., Brum, C. G., Batista, P. P., Gurubaran, S., Pancheva, D., Bageston, J. V., Batista, I. S., and Takahashi, H.: Fast and ultrafast Kelvin wave modulations of the equatorial evening $\mathrm{F}$ region vertical drift and spread F development, Earth Planet. Space, 67, 1, https://doi.org/10.1186/s40623-014-0143-5, 2015.

Ahlquist, J. E.: Normal-Mode Global Rossby Waves: Theory and Observations, J. Atmos. Sci., 39, 193-202, https://doi.org/10.1175/15200469(1982)039<0193:NMGRWT>2.0.CO;2, 1982.

Chen, Y.-W. and Miyahara, S.: Analysis of fast and ultrafast Kelvin waves simulated by the Kyushu-GCM, J. Atmos. Sol.-Terr. Phy., 80, 1-11, https://doi.org/10.1016/j.jastp.2012.02.026, 2012.

Dhanya, R., Gurubaran, S., and Sundararaman, S.: Planetary wave coupling of the mesosphere-lower thermosphere-ionosphere (MLTI) region during deep solar minimum 2005-2008, Indian J. Radio Space, 41, 271-284, 2012.

Forbes, J. M.: Planetary Waves in the ThermosphereIonosphere System, J. Geomagn. Geoelectr., 48, 91-98, https://doi.org/10.5636/jgg.48.91, 1996.

Forbes, J. M. and Zhang, X.: Quasi-10-day wave in the atmosphere, J. Geophys. Res.-Atmos., 120, 11079-11089, https://doi.org/10.1002/2015JD023327, 2015.

Forbes, J. M., Zhang, X., and Bruinsma, S. L.: New perspectives on thermosphere tides: 2. Penetration to the upper thermosphere, Earth Planet. Space, 66, 122, https://doi.org/10.1186/1880-598166-122, 2014

Gan, Q., Yue, J., Chang, L. C., Wang, W. B., Zhang, S. D., and $\mathrm{Du}, \mathrm{J}$.: Observations of thermosphere and ionosphere changes due to the dissipative 6.5-day wave in the lower thermosphere, Ann. Geophys., 33, 913-922, https://doi.org/10.5194/angeo-33913-2015, 2015.

Gasperini, F., Forbes, J. M., and Hagan, M. E.: Wave coupling from the lower to the middle thermosphere: Effects of mean winds and dissipation, J. Geophys. Res.-Space, 122, 7781-7797, https://doi.org/10.1002/2017JA024317, 2017.

Jacobi, C., Jakowski, N., Pogoreltsev, A., Fröhlich, K., Hoffmann, P., and Borries, C.: The CPW-TEC project: Planetary waves in the middle atmosphere and ionosphere, Adv. Radio Sci., 5, 393397, https://doi.org/10.5194/ars-5-393-2007, 2007.

John, S. R. and Kumar, K. K.: Global normal mode planetary wave activity: a study using TIMED/SABER observations from the stratosphere to the mesosphere-lower thermosphere, Clim. Dynam., 47, 3863-3881, https://doi.org/10.1007/s00382-016-30462, 2016.

Jonah, O. F., de Paula, E., Muella, M. T. A. H., Dutra, S. L. G., Kherani, E. A., Negreti, P. M. S., and Otsuka, Y.: TEC variation during high and low solar activities over South American sector, J. Atmos. Sol.-Terr. Phy., 135, 22-35, https://doi.org/10.1016/j.jastp.2015.10.005, 2015.

Laštovička, J.: Forcing of the ionosphere by waves from below, J. Atmos. Sol.-Terr. Phy., 68, 479-497, https://doi.org/10.1016/j.jastp.2005.01.018, 2006.

Lieberman, R. S. and Riggin, D.: High resolution Doppler imager observations of Kelvin waves in the equatorial mesosphere and lower thermosphere, J. Geophys. Res.-Atmos., 102, 26117 26130, https://doi.org/10.1029/96JD02902, 1997.

Lomb, N. R.: Least-squares frequency analysis of unequally spaced data, Astrophys. Space Sci., 39, 447-462, https://doi.org/10.1007/BF00648343, 1976.

Makela, J. J., Meriwether, J. W., Lima, J. P., Miller, E. S., and Armstrong, S. J.: The Remote Equatorial Nighttime Observatory of Ionospheric Regions Project and the International Heliospherical Year, Earth Moon Planets, 104, 211-226, https://doi.org/10.1007/s11038-008-9289-0, 2009.

Mo, X. and Zhang, D.: Quasi-10d wave modulation of an equatorial ionization anomaly during the Southern Hemisphere stratospheric warming of 2002, Ann. Geophys., 38, 9-16, https://doi.org/10.5194/angeo-38-9-2020, 2020.

Pancheva, D. and Laštovička, J.: Planetary wave activity in the lower ionosphere during CRISTA I campaign in autumn 1994 (October--November), Ann. Geophys., 16, 1014-1023, https://doi.org/10.1007/s00585-998-1014-9, 1998.

Pancheva, D., Mitchell, N., Clark, R. R., Drobjeva, J., and Lastovicka, J.: Variability in the maximum height of the ionospheric F2-layer over Millstone Hill (September 1998-March 2000); influence from below and above, Ann. Geophys., 20, 1807-1819, https://doi.org/10.5194/angeo-20-1807-2002, 2002.

Paulino, A., Batista, P., and Clemesha, R.: Lunar tides in the mesosphere and lower thermosphere over Cachoeira Paulista $\left(22.7^{\circ} \mathrm{S} ; 45.0^{\circ} \mathrm{W}\right)$, J. Atmos. Sol.-Terr. Phy., 78-79, 31-36, https://doi.org/10.1016/j.jastp.2011.04.018, 2012.

Paulino, A. R., Batista, P. P., Lima, L. M., Clemesha, B. R., Buriti, R. A., and Schuch, N.: The lunar tides in the mesosphere and lower thermosphere over Brazilian sector, J. Atmos. Sol.-Terr. Phy., 133, 129-138, https://doi.org/10.1016/j.jastp.2015.08.011, 2015.

Paulino, A. R., Lima, L. M., Almeida, S. L., Batista, P. P., Batista, I. S., Paulino, I., Takahashi, H., and Wrasse, C. M.: Lunar tides in total electron content over Brazil, J. Geophys. Res.-Space, 122, 7519-7529, https://doi.org/10.1002/2017JA024052, 2017.

Pedatella, N. M.: Observations and simulations of the ionospheric lunar tide: Seasonal variability, J. Geophys. Res.-Space, 119, 5800-5806, https://doi.org/10.1002/2014JA020189, 2014.

Pedatella, N. M. and Forbes, J. M.: Global structure of the lunar tide in ionospheric total electron content, Geophys. Res. Lett., 37, 106103, https://doi.org/10.1029/2010GL042781, 2010.

Pedatella, N. M., Liu, H.-L., and Richmond, A. D.: Atmospheric semidiurnal lunar tide climatology simulated by the Whole Atmosphere Community Climate Model, J. Geophys. Res.-Space, 117, a06327, https://doi.org/10.1029/2012JA017792, 2012. 
Roberts, J. and Roberts, T. D.: Use of the Butterworth low-pass filter for oceanographic data, J. Geophys. Res.-Oceans, 83, 55105514, https://doi.org/10.1029/JC083iC11p05510, 1978.

Scargle, J. D.: Studies in astronomical time series analysis. II. Statistical aspects of spectral analysis of unevenly spaced data, Astrophys. J., 263, 835-853, https://doi.org/10.1086/160554, 1982.

Smith, A. K. and Perlwitz, J.: Middle Atmosphere|Planetary Waves, pp. 1-11, Academic Press, Oxford, https://doi.org/10.1016/B978-0-12-382225-3.00229-2, 2015.

Takahashi, H., Wrasse, C. M., Denardini, C. M., Pádua, M. B., de Paula, E. R., Costa, S. M. A., Otsuka, Y., Shiokawa, K., Monico, J. F. G., Ivo, A., and Sant'Anna, N.: Ionospheric TEC Weather Map Over South America, Adv. Space Res., 14, 937949, https://doi.org/10.1002/2016SW001474, 2016.
Torrence, C. and Compo, G. P.: A Practical Guide to Wavelet Analysis, B. Am. Meteorol. Soc., 79, 61-78, https://doi.org/10.1175/15200477(1998)079<0061:APGTWA>2.0.CO;2, 1998.

Yamazaki, Y. and Matthias, V.: Large-Amplitude Quasi10-Day Waves in the Middle Atmosphere During Final Warmings, J. Geophys. Res.-Atmos., 124, 9874-9892, https://doi.org/10.1029/2019JD030634, 2019. 